\title{
REVISED ISOSEISMAL MAPS FOR THE 1956 BAY OF PLENTY AND 1987 EDGECUMBE, NEW ZEALAND, EARTHQUAKES - IMPLICATIONS FOR SEISMIC HAZARD AND RISK
}

\author{
David J. Dowrick ${ }^{1}$
}

\begin{abstract}
SUMMARY
The Modified Mercalli intensities of the $1956 M_{\mathrm{w}} 6.3$ Bay of Plenty and $1987 M_{\mathrm{w}} 6.5$ Edgecumbe earthquakes have recently been reviewed and about one-third of them were found to be erroneous. The resulting revisions to their isoseismal maps are substantial, and both new maps now show the strong influence of the high attenuation in the Taupo Volcanic Zone (TVZ). An analysis of the causes of the errors in the intensities is given. The new maps will help improve the modelling of attenuation in the TVZ, and will contribute to improvements in assessments of seismic hazard and risk in that region. An important implication is that the mean damage ratios estimated from studies of damage costs in the Edgecumbe earthquake by Dowrick and Rhoades are likely to be erroneously low, and need to be reviewed.
\end{abstract}

\section{INTRODUCTION}

The $1956 M_{\mathrm{w}} 6.3$ Bay of Plenty earthquake and the $1987 M_{\mathrm{w}}$ 6.5 Edgecumbe earthquake are the largest historical earthquakes to have occurred in the Taupo Volcanic Zone (TVZ). They are thus particularly important in developing an understanding of the seismic hazard and risk in the context of the TVZ. The Edgecumbe earthquake is probably the most studied New Zealand earthquake, with a whole volume of the New Zealand Journal of Geology and Geophysics being devoted to it in 1989, and various papers on it since, eg. Dowrick (1991), Dowrick \& Rhoades (1990; 1993; 1995; 1997) and Webb \& Anderson (1998).

The patterns of the original isoseismal maps of both these earthquakes are unconvincing in some respects. For example, that of the 1956 event, prepared by the New Zealand Seismological Observatory in 1956 and republished in Downes (1995) (Figure 1), shows no marked effect of the high attenuation that occurs in the TVZ, and the distances between the isoseismals appear to be too small.

The original isoseismal map of the 1987 Edgecumbe earthquake was prepared in the New Zealand Seismological Observatory and published as part of a paper by Lowry et al. (1989), (Figure 2). Subsequently some people (eg. G Downes, $\mathrm{D}$ Dowrick and D Spurr) developed concerns about the reliability of some aspects of this map. One result of this concern was the funding by the New Zealand Earthquake Commission (EQC) of a study (inconclusive) by those three people, which compared the isoseismals of the Edgecumbe earthquake with those of the 1994 Northridge, California, earthquake.

In view of his continuing concerns, and the importance of the reliability of the isoseismals to various scientific studies (particularly those related to earthquake hazard and risk), the present author decided to review all of the intensities assigned for these two earthquakes, and to revise the isoseismals as necessary. This work and its implications are discussed below.

\section{REVIEW OF THE INTENSITIES IN THE 1956 BAY OF PLENTY EARTHQUAKE}

This earthquake resulted in only 17 felt reports being submitted to the New Zealand Seismological Observatory (NZSO), with intensities ranging from MM1 to MM5. It was then decided to carry out a special survey, with questionnaires being distributed widely in the north of the North Island. This resulted in felt reports being received from a total of 117 locations where the earthquake was felt. An isoseismal map was produced, as shown in Figure 1. The map shows that, unfortunately, the special survey did not extend to most of the area to the east of the TVZ, when clearly the event was felt over the East Cape region; for example, it was felt at Tolaga Bay on the east coast.

The present author reviewed all of the felt reports and assigned the intensities which are plotted on Figure 3. The resulting isoseismals are very different from the original ones of Figure 1. The new map clearly shows the characteristic

\footnotetext{
${ }^{1}$ Tauranga, New Zealand (Life Member).
} 
indentations in the isoseismals caused by the high attenuation in the TVZ (Dowrick, 2007). Note that in the indentation within the TVZ south of the MM3 isoseismal, the earthquake was reported as having intensity MM2 at Tokoroa and Not Felt at Ngakuru, Atiamuri, Broadlands, Oruanui and Taupo. In addition, in the corresponding indentation in the MM4 isoseismal there are five MM3's and one MM4. The attenuation rate from the source along wave paths to the southwest within the TVZ is consistent with that found for the TVZ by Dowrick \& Rhoades (2005).

On Figure 3 it is also seen that the spacing between the MM3 and MM4 isoseismals to the west of the epicentre is about three times wider than it is on the original map. This indicates attenuation that is consistent with the mean rates estimated in the attenuation model of Dowrick \& Rhoades (2005).

The difference between the 1956 and new maps (Figures 1 and 3 ) is the result of many errors made in assigning the original intensities. The causes of such errors are discussed in relation to the intensities for the 1987 Edgecumbe given below.

It is noted that the source of the earthquake is likely to be on the Wairaka fault or Wairaka Ridge, adjacent seabed features which are close to the epicentre for this earthquake (I. Wright, NIWA, pers. comm). The strike of these seismic sources of $290^{\circ}$ is consistent with the strike of $306^{\circ}$ determined seismologically by Doser \& Webb (2003).

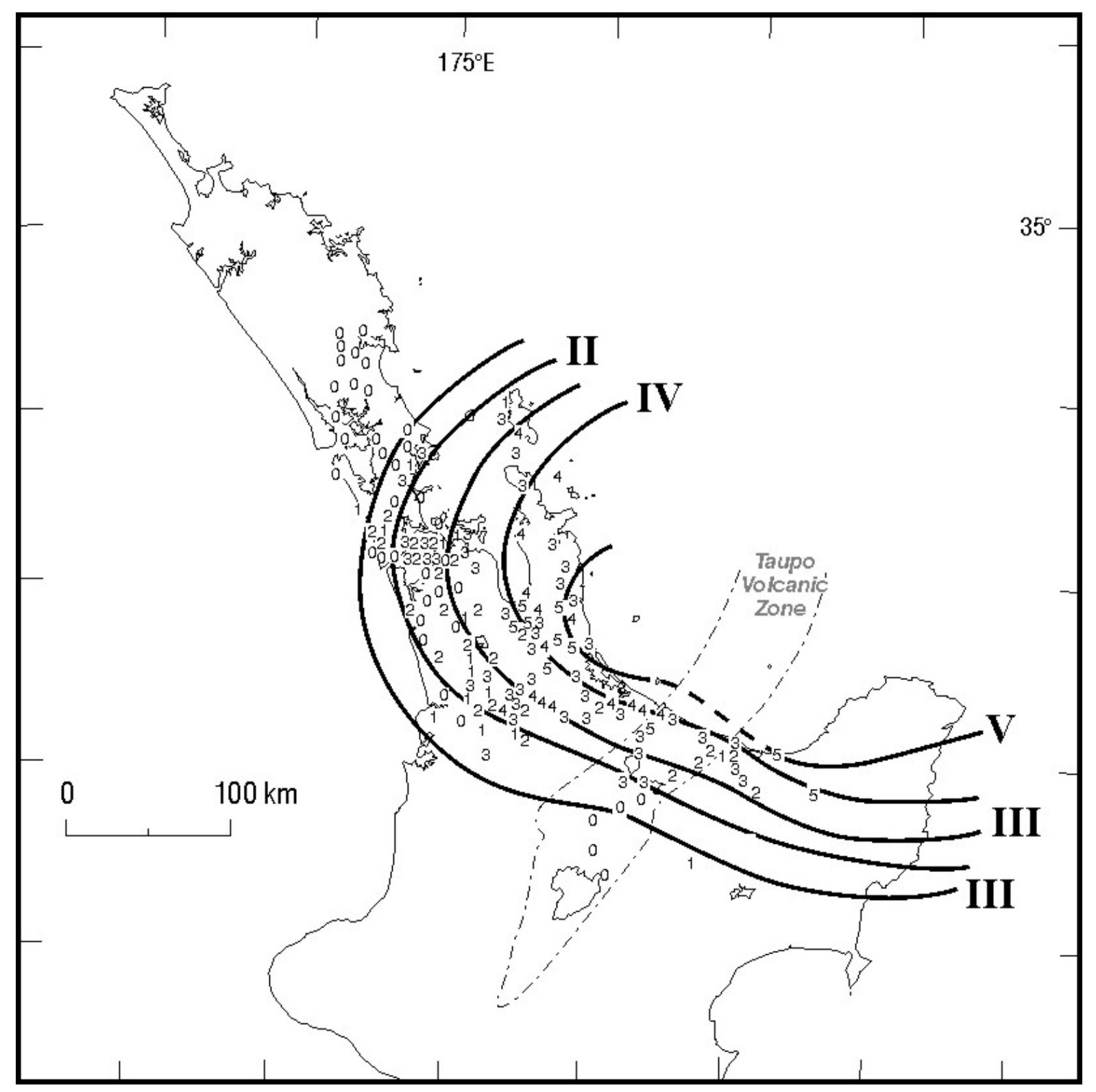

Figure 1. Original isoseismal map of the $1956 M_{\mathrm{w}} 6.3$ Bay of Plenty earthquake (from Downes 1995).

\section{REVIEW OF THE INTENSITIES IN THE 1987 EDGECUMBE EARTHQUAKE}

The data on which the intensities were assigned was recorded on the standard "felt report" forms issued by the NZSO. The criteria on these forms were based on the then current New Zealand scale for Modified Mercalli intensity, as published by
Eiby (1966). The forms sent in to the NZSO came in two waves, the first comprising those from regular reporters, and the second comprising responses to a public appeal for more reports. In total about 520 felt report forms were received, about 290 of which were from people reporting that they had not felt the earthquake. 
The first task was to review the non-zero intensities (c. 230) that had been assigned. This involved using the criteria of the now accepted New Zealand MM intensity scale (of Dowrick, 1996). To make the review as robust as possible, the procedure adopted was as follows:

(1) Do my own assessment of intensity (first pass) for all of the forms.
(2) Put the forms in sets for each intensity level.

(3) Check each set for internal comparability and consistency of all of the intensities assigned.

(4) Double check all of the forms where I had revised the intensity.
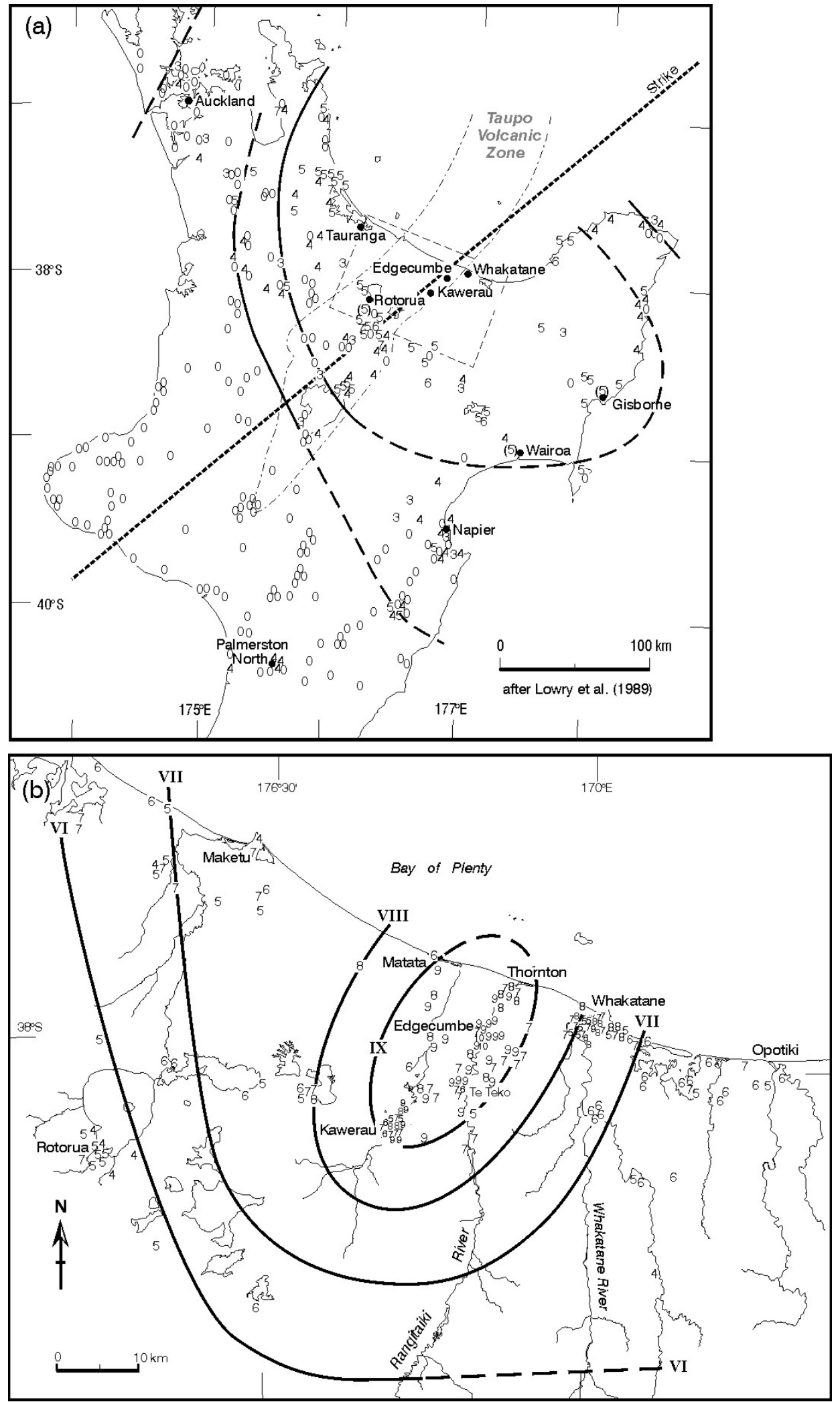

Figure 2. Original isoseismal maps of the $1987 M_{w} 6.5$ Edgecumbe earthquake: (a) overall map, and (b) inner isoseismals (after Lowry et al. (1989)). 


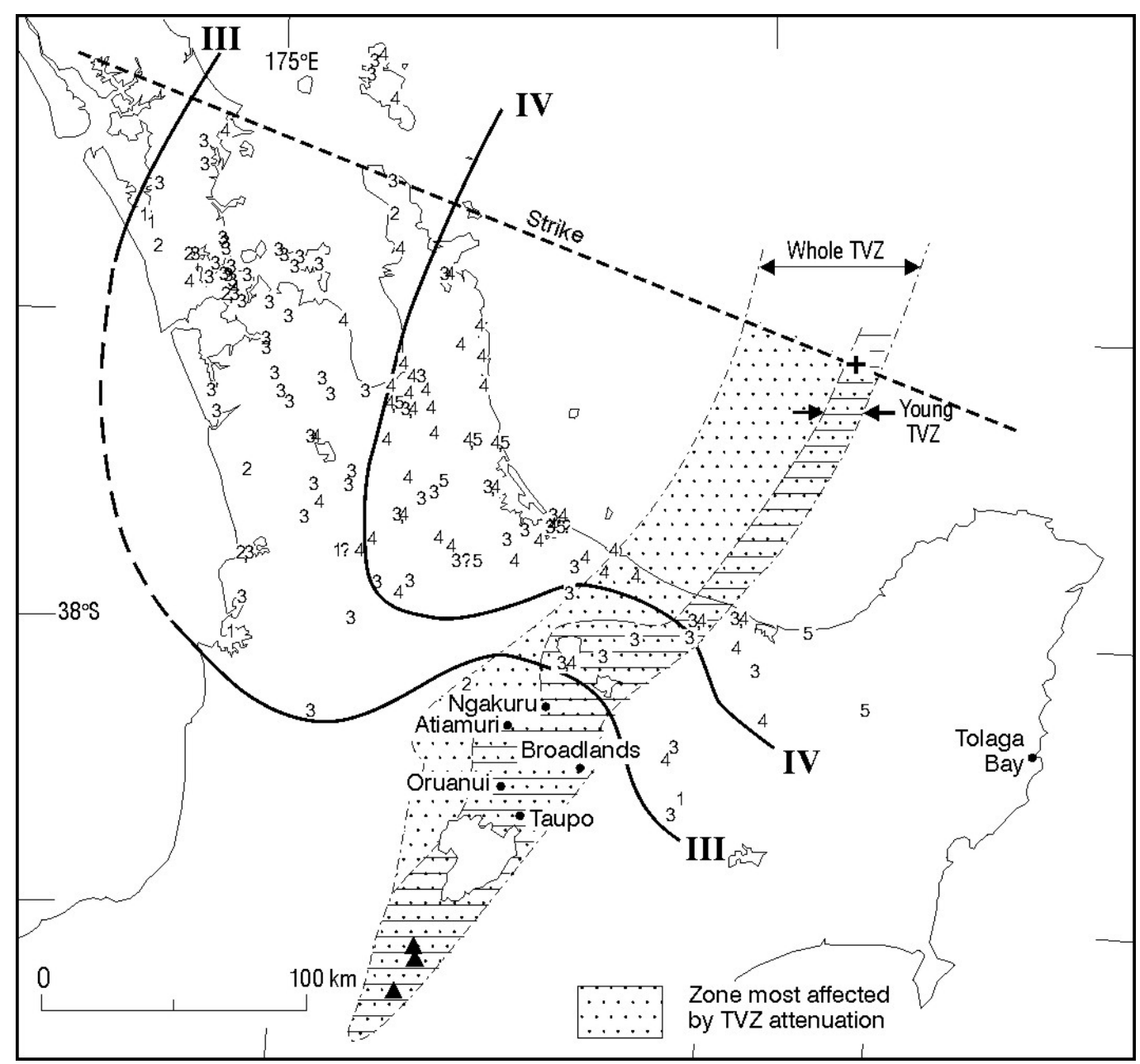

Figure 3. Revised isoseismal map of the $1956 M_{w} 6.3$ Bay of Plenty earthquake (this study).

In addition, duplications of reporting were discarded. Duplication arose from: (a) the two waves of reporting, and (b) more than one observer reporting on the same property.

Further corrections and improvements arose from:

(1) Checking the geographic location of the observer assigned by the NZSO on all forms, and correcting where necessary.

(2) Finding the latitude/longitude location of observers with otherwise vague rural addresses. Through my knowledge of the region, good topographical maps, and telephoning, this fortunately proved possible in all cases despite the earthquake reports having been made nearly 20 years ago.

Next consider the nature and incidence of the errors in the intensity assignments. Excluding the 20 or so duplications, and three invalid intensities, there were 211 useful reports. While a modest number of differences were expected between the new and the original intensities, the error rate which was found, ie. 33 percent, was abnormally and surprisingly high. A comparison of the new and original intensities is made in graphical form in Figure 4. Here is shown the scatter of the original intensities with respect to the revised intensities. Also plotted on this graph are the mean values of the original intensities corresponding to the revised values. It is seen that the original values tended to be higher on average for intensities less than MM6, and erred on the low side for intensities greater than MM6.

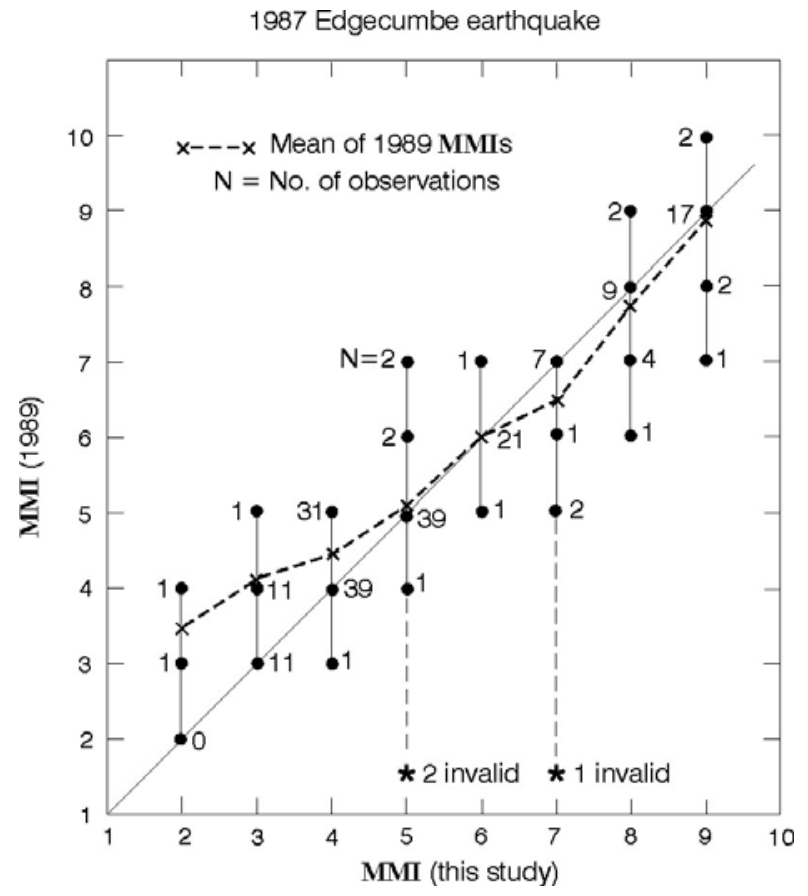

Figure 4. Comparative plot of the original 1989 intensities in the Edgecumbe earthquake with the revised intensities (this study). 
While the overall error rate was 33\%, the error rate varied considerably with intensity. As seen on Figure 5, the least deviation occurred at MM7 (2\% error) while the largest (significant) error rate was $52 \%$ at MM3. The error rate at MM2 is ignored here because it arises from only two observations. Overall it is seen that the original assigners of intensity had most trouble assigning the same values as in this study at intensities MM3, MM4, MM8 and MM9. As no structural engineer was involved in the assignments, the errors at MM8 and MM9 are not surprising, but this does not explain the problems at low intensities (for which, see Items 2 and 6 below).

1987 Edgecumbe earthquake

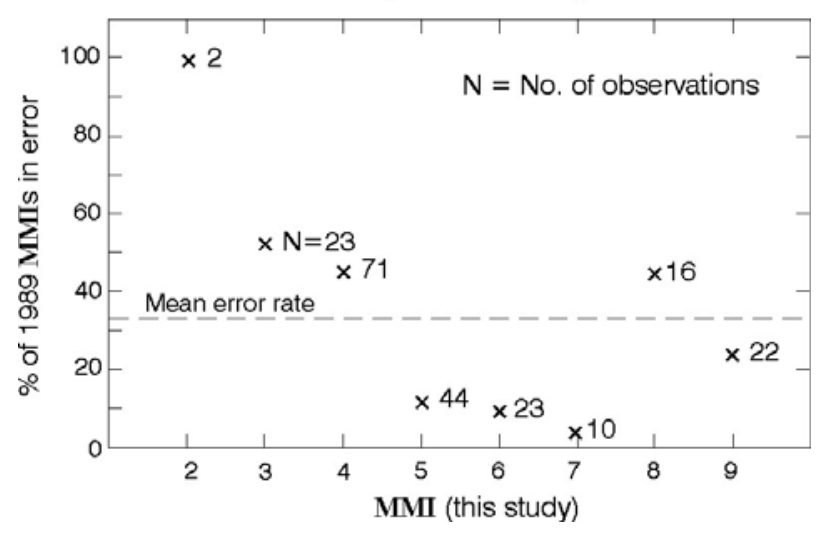

Figure 5. Plot of percentages of the original 1989 intensities in the Edgecumbe earthquake which were in error, as a function of intensity.

Next consider the main sources of the errors in the original intensities, as follows:

(1) No involvement of a structural engineer in the assignment of the damaging intensities.

(2) Inconsistency/errors in interpretation of MM criteria. This occurred mainly at lower intensities. It would appear that appropriate checking was not carried out by senior staff. As an example, in a report from Lake Rotoma, the intensity was assigned as MM5, whereas some things fell from shelves, which is an indicator of MM6.

(3) There were a few cases of use of some criteria from the 1966 MM scale that have since been deleted from the current (1996) scale. These are not errors in terms of the original assignments, but caused discrepancies with the present assignments.

(4) Intensities observed above ground floor in buildings were not reduced to ground level intensity to compensate for storey height amplification, where such a report does not also contain effects noticed on the ground floor which control the intensity. For simplicity, I have reduced such intensities by one unit in eight such cases. I know of frequent instances (including my own experiences) of earthquakes having been not felt on the ground floor but being felt on upper floors. Two of the cases from this earthquake come from Tuai and Palmerston North. Tuai is in the middle of the MM5 zone north-west of Wairoa (Figure 7(a)), and was observed on the third storey of the power house. This observation was assigned as MM6, and changed in the present study to MM5. In Palmerston North the earthquake was reported from the fifth storey of a building housing the telephone exchange. From this report the intensity was assigned as MM4, and changed in the present study to MM3. As seen on Figure 7(a), Palmerston North is in the south of the MM3 zone, and MM3 was assigned for the nearby location of Himatangi Beach.

(5) Use of "criteria" which were not part of the 1966 (or 1996) MM scale. There were three instances of this, as indicated by "invalid" on Figure 5. One of these cases comprised the assignment of MM7 at the hot pools on Wharepapa Road near Reporoa, because the same "hot pools became active mud pools and some changed colour". There was nothing to suggest shaking stronger than about intensity MM4 in that vicinity (see Figure 7(a), c. $35 \mathrm{~km}$ south of Rotorua). It is also noted that it is common for hot/mud pools to have marked changes in behaviour, for no visible reason.

(6) Undue weight given to inherently unreliable subjective criteria relating to human alarm. In particular, this resulted in many reports being assigned as MM5, when all the other phenomena noted indicated MM4 or less. Another unreliable criterion for MM5 is "the stopping of clocks". This should not be used if at all possible, as I have found various instances in other earthquakes, where clocks have stopped when other criteria strongly support the intensity being MM4 or MM3.

(7) The Felt Report form in use at the time was inadequately worded, and easily misinterpreted. The form was completely reworded by Gaye Downes and adopted by the Institute of Geological and Nuclear Sciences (now GNS Science) and started to be used in 2002.

As the final illustration of the differences between the original and new intensities, the numbers of assignments of each intensity level in the two studies are plotted on Figure 6. This figure reproduces the data on Figure 5 in a simplified form and highlights the two numerically largest discrepancies, arising from the original assignment of too many MM5s, many of which should have been MM4.

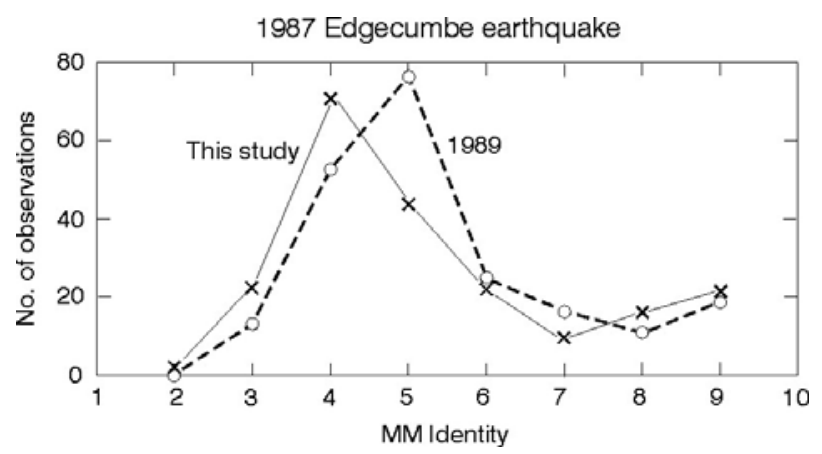

Figure 6. Comparative plot of the count of each intensity in the Edgecumbe earthquake (MM2- MM9) assigned in the 1989 study and in this study. The biggest discrepancies (numerically) are at intensities MM4 and MM5.

The revised isoseismal map on Figure 7(a) now clearly exhibits, in the MM4 and MM5 isoseismals, the characteristic indentation caused by the high attenuation in the TVZ. The same effect has already been shown above in the isoseismals of the 1956 Bay of Plenty earthquake (Figure 3), and the attenuation rate for wave paths within the TVZ on Figure 7 is also consistent with that found for the TVZ by Dowrick \& Rhoades (2005). On Figure 7(a), the vector A represents the wave path travelling from the source south-westwards, and just within the Main Seismic Region (MSR) along its route 
adjacent to the TVZ. Near vector A, the south-western corners of the MM4 and MM5 isoseismals (locations marked B and C on the map) are drawn (dashed lines) to conform to the attenuation rate of the MSR, in the absence of nearby intensity observations in the MSR. It is noted that there would be few, if any, observers within the unpopulated zone indicated on the map. It is stressed that an intensity of MM4 at point B is likely because intensities of MM4 were reported from locations south from Napier, ie at Hastings and near Poukawa, which are nearly the same distance from the source as point $\mathrm{B}$.
If the south-western portions of the MM4 and MM5 isoseismals were conventionally drawn closer to the observations, they would pass through points $\mathrm{D}$ and $\mathrm{E}$ respectively.

On Figure $7(\mathrm{~b})$ it is seen that the areas within the higher intensity isoseismals (MM8 and MM9) are smaller now than previously (Figure 2(b)).
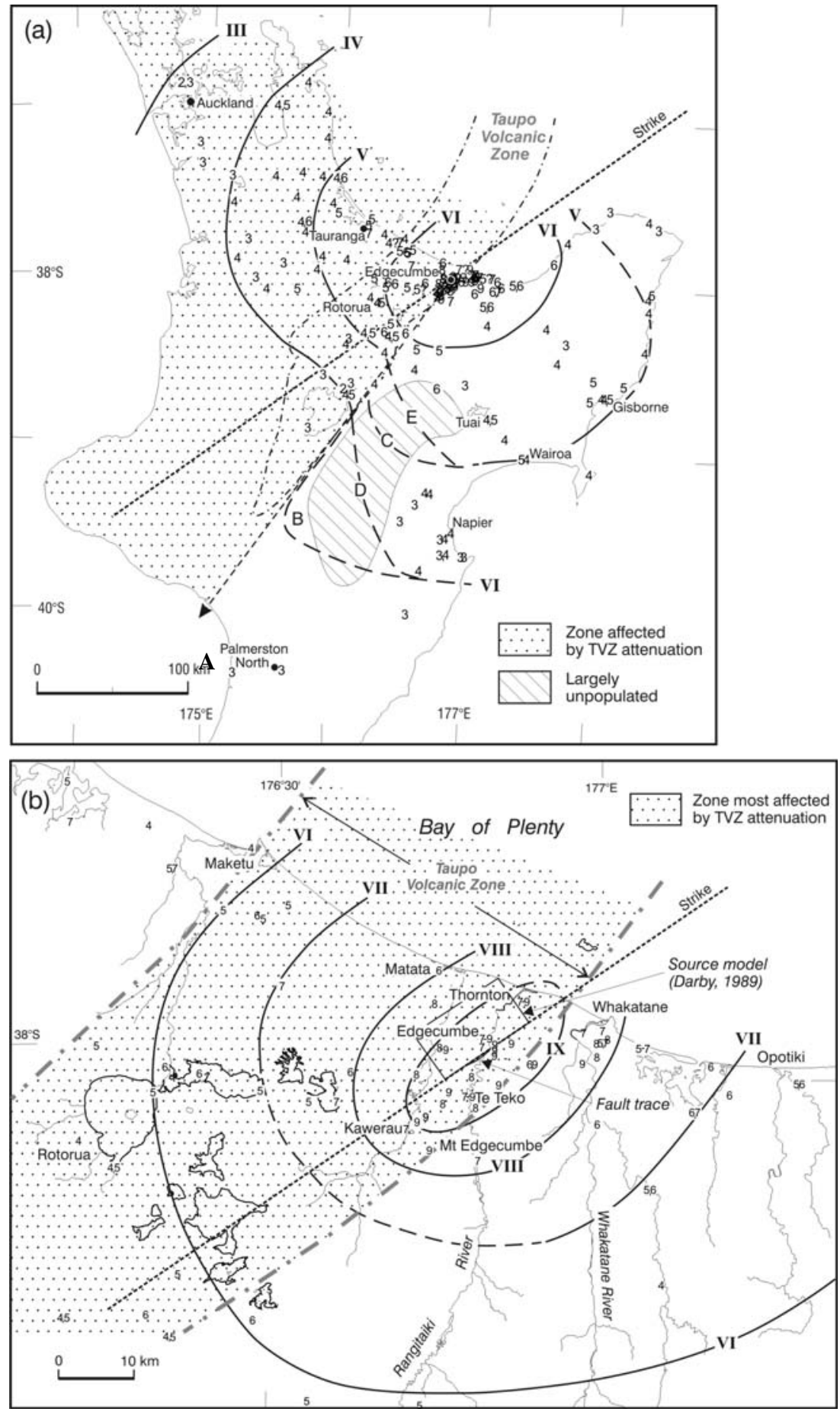

Figure 7. Revised isoseismal maps of 1987 Edgecumbe earthquake (this study) (a) overall map, and (b) inner isoseismals. 


\section{IMPLICATIONS OF THE REVISED ISOSEISMAL MAPS}

The new isoseismal maps have implications for seismic hazard and risk assessment studies.

First, the isoseismal dimensions within the TVZ will help to give more robust models of attenuation of intensity within the TVZ. This will be done in a revision of the attenuation models of Dowrick \& Rhoades (2005).

Second, the mean damage ratios estimated in past studies of this earthquake are likely to be erroneously low, as a direct consequence of the areas within most of the original isoseismals having been too large. This means that most of the isoseismals are closer to the source, and hence relate to stronger ground shaking. In an unpublished sensitivity test carried out (c. 1990) on the damage ratios for houses, the MM9 isoseismal was moved inwards by about $2 \mathrm{~km}$, and the mean damage ratios were recalculated. It was found that the mean damage ratios for the new MM8 and MM9 zones both increased by about 25 percent over the original values.

As a consequence the Dowrick \& Rhoades studies of 1993, 1995 and 1997 need to be reviewed.

\section{CONCLUSIONS}

As a result of the above study of the intensities in the $1956 M_{\mathrm{w}}$ 6.3 Bay of Plenty and the $1985 M_{\mathrm{w}} 6.5$ Edgecumbe earthquakes, the following conclusions have been drawn:

(1) Substantial numbers of errors have been found in the intensities assigned for both of these earthquakes, 33 percent being erroneous in the case of the Edgecumbe event.

(2) The causes of the errors were manifold, with seven main causes being identified. One of the main causes was the wording of the Felt Report form, which has subsequently been greatly improved.

(3) The new isoseismals for both earthquakes exhibit characteristic indentations in the vicinity of the TVZ, caused by the high attenuation in the TVZ. The attenuation rate within the TVZ in both earthquakes is consistent with that found for the TVZ by Dowrick \& Rhoades (2005).

(4) The inner isoseismals of the Edgecumbe earthquake are mostly substantially smaller than those of the original map. This implies that the mean damage ratios estimated by Dowrick \& Rhoades in a series of studies of the damage costs of this earthquake are likely to be erroneously low, and need to be reviewed.

(5) By revising the attenuation rates for the TVZ, and the damage ratios for the Edgecumbe earthquakes, more reliable seismic hazard and risk assessments for this region will be possible.

\section{ACKNOWLEDGEMENTS}

The author thanks Jim Cousins, Kevin Fenaughty and Les Megget for their reviews of the manuscript of this paper.

\section{REFERENCES}

Doser, D.I. and Webb, T.H. (2003). "Source parameters of large historic (1917 - 1961) earthquakes, North Island, New Zealand”. Geophysical journal international 152: 795-832.

Downes, G.L. (1995). "Atlas of isoseismal maps of New Zealand earthquakes”. Institute of Geological Sciences Ltd.

Dowrick, D.J. (1991)."Damage costs for houses and farms as a function of intensity in the 1987 Edgecumbe earthquake”. Earthquake Engineering and Structural Dynamics 20: 455-469.

Dowrick, D.J. (1996). “The Modified Mercalli intensity scale - Revisions arising from recent studies of New Zealand earthquakes". Bulletin of the New Zealand National Society for Earthquake Engineering 29(2): 92-106.

Dowrick, D.J. (2007). "Effects of attenuation in the Taupo Volcanic Zone of spatial distribution of ground shaking in New Zealand earthquakes”. New Zealand Journal of Geology and Geophysics, December, 50: 315-325.

Dowrick, D.J. and Rhoades, D.A. (1990). "Damage ratios for domestic buildings in the 1987 Edgecumbe earthquake". Bulletin of the New Zealand National Society for Earthquake Engineering 23: 137-149.

Dowrick, D.J. and Rhoades, D.A. (1993). "Damage costs for commercial and industrial property as a function of intensity in the 1987 Edgecumbe earthquake". Earthquake Engineering and Structural Dynamics 22: 869-884.

Dowrick, D.J. and Rhoades, D.A. (1995). "Damage ratios for plant, equipment and stock in the 1987 Edgecumbe, New Zealand earthquake". Bulletin of the New Zealand National Society for Earthquake Engineering 28(4): 265278.

Dowrick, D.J. and Rhoades, D.A. (1997). "Vulnerability of different classes of low-rise buildings in the Edgecumbe, New Zealand”, earthquake. Bulletin of the New Zealand National Society for Earthquake Engineering 30(3): 227241.

Dowrick, D.J. and Rhoades, D.A. (2005). "Revised models of attenuation of Modified Mercalli intensity in New Zealand earthquakes”. Bulletin of the New Zealand Society for Earthquake Engineering 38(4): 185-214.

Eiby, G.A. (1966). "The Modified Mercalli scale of earthquake intensity and its use in New Zealand". New Zealand Journal of Geology and Geophysics 9: 122-129.

Lowry, M.A., Ede, S.C. and Harris, J.S. (1989). “Assessment of seismic intensities resulting from the 197 Edgecumbe earthquake, New Zealand, and implications for modernising the intensity scale”. New Zealand Journal of Geology and Geophysics 32(1): 145-154.

Webb, T.H. and Anderson, H. (1998). "Focal mechanisms of large earthquakes in the North Island of New Zealand: slip partitioning at an oblique active margin”. Geophysical Journal International 134; 40-86. 